\title{
Multi-drug resistant Salmonella enterica serovar Typhi isolates with reduced susceptibility to ciprofloxacin in Kenya
}

\author{
Winnie C. Mutai ${ }^{1 *} \mathbb{D}$, Anne W. T. Muigai ${ }^{2}$, Peter Waiyaki ${ }^{3}$ and Samuel Kariuki ${ }^{3}$
}

\begin{abstract}
Background: Typhoid fever remains a public health concern in developing countries especially among the poor who live in informal settlements devoid of proper sanitation and clean water supply. In addition antimicrobial resistance poses a major challenge in management of the disease. This study assessed the antimicrobial susceptibility patterns of Salmonella enterica serotype Typhi (S. Typhi) isolated from typhoid fever cases (2004-2007).

Methods: A cross sectional study was conducted on 144 archived S. Typhi isolates (2004-2007) tested against 11 antimicrobial agents by quality controlled disk diffusion technique. Isolates resistant to ampicillin, chloramphenicol, and cotrimoxazole were considered Multidrug resistant (MDR). Thirty MDR isolates were selected randomly and further tested using minimum inhibitory concentration (MIC) E-test.

Results: Sixteen percent (23/144) of the isolates were susceptible to all the antibiotics tested while $68 \%$ were resistant to three or more of the 11 antibiotics tested. The isolates showed a high susceptibility to ceftriaxone (94\%) and gentamicin (97\%). A high percentage of resistance was observed for the conventional first-line antibiotics; ampicillin (72\%), chloramphenicol (72\%), and cotrimoxazole (70\%). Sixty-nine percent of the isolates (100/144) showed reduced susceptibility to ciprofloxacin. All the $30(100 \%)$ isolates selected for MIC test were susceptible to amoxicillin-clavulanic acid. All except one of the 30 isolates were susceptible to ceftriaxone while majority $21(70 \%)$ recorded an intermediate susceptibility to ciprofloxacin with MIC of $0.12-0.5 \mu \mathrm{g} / \mathrm{mL}$.
\end{abstract}

Conclusion: A large proportion of S. Typhi isolates were MDR and also showed reduced susceptibility to ciprofloxacin. Fluoroquinolone resistance is emerging and this may pose a challenge in treatment of typhoid in future. There is need for routine surveillance to monitor this phenotype in clinical settings.

Keywords: Multi drug resistance in Kenya, Salmonella enterica serotype Typhi, Ciprofloxacin

\section{Introduction}

Typhoid fever posses a public health threat, recording high morbidity and mortality rates mainly in developing countries [1,2]. Current published data on typhoid fever shows an annual global estimate of 20.6 million cases and 223000 deaths. In sub-Saharan Africa, the incidence of typhoid fever is greater than 100 per 100,000 persons per year resulting in 33, 490 deaths accounting for $26 \%$ of global typhoid deaths in Africa [3]. Incidence may vary from one country to another due to dynamics in risk factor exposure levels attributed to the disease; some

\footnotetext{
* Correspondence: winny@uonbi.ac.ke

${ }^{1}$ Department of Medical Microbiology, University of Nairobi, Nairobi, Kenya Full list of author information is available at the end of the article
}

countries like Egypt report low incidence rate (13/ 100,000-59/100,000 persons annually) [4-6] while others like Kenya have reported high adjusted incidence rate of up to 247 cases per 100,000 persons in an informal settlement [7]. These figures may, however, be overestimated based on the controlled risk factors. The ongoing 'Typhoid Fever Surveillance in Africa' study may probably give the accurate estimate [8].

The high incidence rates of typhoid fever have been exacerbated by the emergence of $S$. Typhi strains resistant to antibiotics recommended for treatment. Centers for Disease Control and Prevention (CDC) ranks antibiotic resistant $S$. Typhi as a serious threat that requires frequent monitoring and prevention to reduce the spread 
of the resistant strains [9]. In the past, first line antibiotics for the treatment of typhoid included chloramphenicol, ampicillin, and trimethoprim-sulphamethoxazole. However, Multidrug resistant (MDR) S. Typhi, defined as strains resistant to these first-line antibiotics emerged in the late 1980s [10, 11]. This resulted in the use of fluoroquinolones and third generation cephalosporins as alternatives for treatment of MDR S. Typhi cases.

Increased use of fluoroquinolones such as ciprofloxacin for treatment has resulted in the emergence of strains resistant or with reduced susceptibility to this particular antibiotic [12]. Other than the use of these antibiotics in the treatment of human cases, there have been many reports on the use of antibiotics in treatment of animal disease and as growth promoters in food derived from animals which similarly contribute to the occurrence and spread of antibiotic resistant bacteria [13].

Based on the current revised Clinical and Laboratory Standards Institute (CLSI) guidelines it is important to have a clear picture of the situation regarding resistance, especially to ciprofloxacin. This study aimed at determining the antimicrobial susceptibility patterns of archived isolates of $S$. Typhi isolated from blood samples.

\section{Material and methods Study design}

This was a cross sectional study where 144 S. Typhi archived isolates collected between 2004 and 2007 were analysed.

\section{Bacterial isolation}

The isolates were obtained from blood samples of patients presenting with typhoid fever at Aga Khan University Hospital, Nairobi (AKUH) and Kenyatta National Hospital (KNH), both located in Nairobi, Kenya. The archived isolates were randomly selected and subcultured on MacConkey agar to check for purity. Confirmed S. Typhi isolates were stored at $-70{ }^{\circ} \mathrm{C}$ on freezing media until analyzed. The study was approved by KEMRI Scientific Steering Committee (SSC No. 1320).

\section{Antibiotic susceptibility testing}

Discrete $S$. Typhi isolates were tested for susceptibility to various antimicrobials agents by quality controlled disk diffusion technique based on the CLSI guidelines [14]. The antibiotics (Oxoid Ltd., Basingstoke, United Kingdom) screened included; ampicillin (10 $\mu \mathrm{g})$, amoxicillin-clavulanic acid $(30 \mu \mathrm{g})$, cefuroxime $(30 \mu \mathrm{g})$, ceftriaxone $(30 \mu \mathrm{g})$, cefotaxime $(30 \mu \mathrm{g})$ ciprofloxacin $(5 \mu \mathrm{g})$, nalidixic acid $(10 \mu \mathrm{g})$, tetracycline $(30 \mu \mathrm{g})$, chloramphenicol $(30 \mu \mathrm{g})$, cotrimoxazole $(25 \mu \mathrm{g})$ and gentamicin $(10 \mu \mathrm{g})$. The results were interpreted as sensitive, intermediate or resistant in accordance with CLSI guidelines [14]. Escherichia coli ATCC 25922 was used as the control strain.

\section{Case definition}

MDR strains were defined as isolates resistant to ampicillin, chloramphenicol, and cotrimoxazole.

\section{Determination of minimum inhibitory concentrations}

Thirty $S$. Typhi isolates that were resistant to ciprofloxacin, ceftriaxone, cefotaxime, amoxicillin-clavulanic acid, nalidixic acid and chloramphenicol by disc diffusion technique were randomly selected from the $98 \mathrm{MDR}$ isolates for MIC determination. The MICs of the antibiotics were determined by E-test guided by the manufacturer's instructions (AB Biodisk, Solna, Sweden). The cutoff MIC provided by CLSI guidelines were used to interpret the results. Escherichia coli ATCC 25922 was used to control for growth of test strains and potency of the E-test strips [14].

\section{Data analysis}

Data generated from this study was entered on MS excel and analyzed using SPSS version 22. The zone of inhibition by disc diffusion was measured in millimeters and interpreted as susceptible, intermediate or resistant based on the CLSI standards. The MIC results of E-test were also categorized as susceptible, intermediate or resistant. Frequency of multidrug resistance isolates was categorized by year of isolation and phenotypes.

\section{Results}

\section{Antibiotic susceptibility profile}

A total of 144 archived and confirmed S. Typhi isolates were analysed, 115 were obtained from Aga Khan University Hospital and 29 from Kenyatta National Hospital. Twenty three isolates were fully susceptible to all the antibiotics tested. Most of the isolates tested recorded a high susceptibility to ceftriaxone (94\%), gentamicin (97\%), cefotaxime (83\%) and amoxicillin-clavulanic acid (81\%). A high resistant rate was observed among the first-line antibiotics, ampicillin (72\%), chloramphenicol (72\%) and cotrimoxazole (70\%). Sixty-nine percent of the isolates showed an intermediate susceptibility to ciprofloxacin while $6 \%$ were fully resistant. Antibiotic susceptibility test for the 144 isolates is summarized in Table 1.

\section{Multi- drug resistant $S$. Typhi}

Ninety eight $(68 \%)$ of the isolates were MDR. The highest MDR phenotype observed were those resistant to four drugs (98.6\%). The frequency of MDR isolates seemed to be reducing from 2004 to 2007 and this was reflected in both hospitals as shown in Table 2 . 
Table 1 Antibiotic susceptibility patterns among the 144 S. Typhi isolates

\begin{tabular}{llll}
\hline Drug & $\begin{array}{l}\text { Susceptible } \\
\text { Number (\%) }\end{array}$ & $\begin{array}{l}\text { Intermediate } \\
\text { Number (\%) }\end{array}$ & $\begin{array}{l}\text { Resistant } \\
\text { Number (\%) }\end{array}$ \\
\hline Amoxycillin-clavulanic acid & $117(81)$ & $8(6)$ & $19(13)$ \\
Ampicillin & $34(24)$ & $6(4)$ & $104(72)$ \\
Cefotaxine & $120(83)$ & $16(11)$ & $8(6)$ \\
Ceftriaxone & $136(94)$ & $3(2)$ & $5(4)$ \\
Chloramphenicol & $39(27)$ & $1(1)$ & $104(72)$ \\
Cefuroxime & $98(68)$ & $38(27)$ & $8(6)$ \\
Ciprofloxacin & $35(24)$ & $100(69)$ & $9(6)$ \\
Gentamicin & $140(97)$ & $0(0)$ & $4(3)$ \\
Nalidixic acid & $102(71)$ & $32(22)$ & $10(7)$ \\
Tetracycline & $37(26)$ & $2(1)$ & $105(73)$ \\
Cotrimoxazole & $41(29)$ & $2(1)$ & $101(70)$ \\
\hline
\end{tabular}

\section{Minimum inhibitory concentration}

All the $30(100 \%)$ isolates selected for MIC test were susceptible to amoxycillin-clavulanic acid. About 97\% were susceptible to ceftriaxone. Five isolates were resistant to cefotaxime (17\%) and fourteen (47\%) were resistant to chloramphenicol. Of the nine isolates that were resistant to ciprofloxacin by disc diffusion only four exhibited complete resistance to ciprofloxacin (13\%) with a MIC $\geq 1 \mu \mathrm{g} / \mathrm{mL}$. The majority (70\%) of the isolates tested recorded intermediate susceptibility with MIC of $0.12-$ $0.5 \mu \mathrm{g} / \mathrm{mL}$. In addition from the 10 isolates resistant to nalidixic acid by disc diffusion, resistance was observed in six isolates (MIC $\geq 32 \mu \mathrm{g} / \mathrm{mL}$ ) while 24 of the isolates tested were fully susceptible (MIC $<16 \mu \mathrm{g} / \mathrm{mL}$ ) (Table 3).

Table 2 Distribution of MDR S. Typhi

\begin{tabular}{llll}
\hline Parameter & \multicolumn{1}{l}{$\begin{array}{l}\text { Aga-Khan University } \\
\text { Hospital } N=115(\%)\end{array}$} & $\begin{array}{l}\text { Kenyatta National } \\
\text { Hospital } N=29(\%)\end{array}$ & $\begin{array}{l}\text { Total no. of } \\
\text { MDR isolates }\end{array}$ \\
\hline $\begin{array}{l}\text { No. of MDR } \\
\text { S. Typhi }\end{array}$ & $75(65 \%)$ & $23(79 \%)$ & $98(68 \%)$ \\
$\begin{array}{l}\text { Year of isolation } \\
2004(n=59)\end{array}$ & $31(53 \%)$ & $17(29 \%)$ & $48(81 \%)$ \\
$2005(n=47)$ & $25(53 \%)$ & $4(9 \%)$ & $29(62 \%)$ \\
$2006(n=37)$ & $19(51 \%)$ & $2(5 \%)$ & $21(56 \%)$ \\
$2007(n=1)$ & $0(0 \%)$ & $0(0 \%)$ & $0(0 \%)$ \\
No. of resistant antibiotics & & $3(37.5 \%)$ \\
$3(n=8)$ & $3(37.5 \%)$ & $0(0 \%)$ & $68(98.6 \%)$ \\
$4(n=69)$ & $58(84 \%)$ & $10(14.5 \%)$ & $20(91 \%)$ \\
$5(n=22)$ & $10(45.5 \%)$ & $10(45.5 \%)$ & $4(100 \%)$ \\
$6(n=4)$ & $3(75 \%)$ & $1(25 \%)$ & $1(50 \%)$ \\
$7(n=2)$ & $0(0 \%)$ & $1(50 \%)$ & $1(100 \%)$ \\
$9(n=1)$ & $1(100 \%)$ & $0(0 \%)$ & $1(100 \%)$ \\
$11(n=1)$ & $0(0 \%)$ & $1(100 \%)$ &
\end{tabular}

Table 3 Minimum inhibitory concentrations to antimicrobials

\begin{tabular}{llll}
\hline Antibiotic & $\begin{array}{l}\text { Susceptible } \\
(\%)\end{array}$ & $\begin{array}{l}\text { Intermediate } \\
(\%)\end{array}$ & $\begin{array}{l}\text { Resistant } \\
(\%)\end{array}$ \\
\hline Cefotaxime & $23(77)$ & $2(6)$ & $5(17)$ \\
Chloramphenicol & $16(53)$ & - & $14(47)$ \\
Ciprofloxacin & $5(17)$ & $21(70)$ & $4(13)$ \\
Ceftriaxone & $29(97)$ & $1(3)$ & $0(0)$ \\
Nalidixic acid & $24(80)$ & - & $6(20)$ \\
Amoxycillin-clavulanic acid & $30(100)$ & $0(0)$ & $0(0)$ \\
\hline
\end{tabular}

\section{Discussion}

Following the analysis of the trends in susceptibility pattern of $S$. Typhi, the results from this study showed that only a small percentage $(16 \%)$ of the isolates were susceptible to all the eleven drugs tested while $96 \%$ were resistant to one or more of the eleven antibiotics tested. Over the years prevalence of MDR $S$. Typhi has been on the increase in Kenya since it was first reported in 1997-1999 where then the prevalence of MDR phenotype was estimated at 50 to $65 \%$ [15]. The prevalence has since then been on the increase based on the previous studies that have been conducted. In 2001-2002 a prevalence of 70 to $78 \%$ of MDR S. Typhi was reported [16] and in 2010 Mengo and colleagues recorded a prevalence of $70 \%$ [17]. These figures are consistent with what was reported in this study where $68 \%$ of the isolates were MDR (Table 2). This is however in contrast to a study from a tertiary Care Hospital in Coastal Karnataka, India, that reported an MDR proportion of $1.94 \%$ of $S$. Typhi isolates from blood samples [18] while other studies in Nepal have recorded no MDR strains [19]. Over the counter prescription, self-medication and unrestricted use of these drugs may have driven the consistent increase in the prevalence of MDR strains [20]. The use of antibiotics such as tetracyclines, sulfonamides and trimethroprime, nitrofurans, aminoglycosides, $\beta$-lactams, and quinolones by farmers as growth promoters for livestock production could also be predisposing individuals to resistant pathogens $[13,20]$.

In our study a high proportion of the isolates were resistant to the conventional first line antibiotics (ampicillin (72\%)' cotrimoxazole (70\%) and chloramphenicol (72\%). Previously, Mengo et al. also recorded high resistance to ampicillin (75\%)' cotrimoxazole (73\%) and chloramphenicol (74\%) in Kenya [17]. Contrary to the current research on antibiogram of $S$. Typhi, the bacterium is showing full sensitivity to these antibiotics since they had not been used for a long time to treatment typhoid fever [21]. A study in Nepal reported an increased susceptibility rate of chloramphenicol, co-trimoxazole, and ampicillin as 98.8, 98.8, and 97.6\% respectively [22]. These rates are quite high and show promising reemergence of 
strains susceptible to these drugs that can then be reconsidered for the treatment of typhoid fever.

Ciprofloxacin has been used as an alternative antibiotic in the treatment of MDR cases. However, with the currently reviewed breakpoints of ciprofloxacin by CLSI, there has been a rather increase of isolates resistant or recording reduced sensitivity to this antibiotic. In this study, MIC results of ciprofloxacin showed that $13 \%$ of the isolates were resistant. Reduced susceptibility to ciprofloxacin, poses a serious threat to the treatment failure of typhoid fever, especially in developing countries. Similar findings have been reported in other African countries. In Malawi $100 \%$ of all the isolates tested were MDR and 10\% were resistant to nalidixic acid. In the Democratic Republic of Congo 30\% were MDR of which $15 \%$ showed nalidixic acid resistance and decreased susceptibility to ciprofloxacin [23, 24]. Based on a National Typhoid and Paratyphoid Fever Surveillance System (NTPFS) in the US among travelers 69\% showed reduced susceptibility to nalidixic acid of which $99 \%$ of these were either resistant to ciprofloxacin or showed reduced susceptibility [25]. One study in India recorded a $98 \%$ of resistance to nalidixic acid among $S$. Typhi isolates from blood cultures [26] this same study reported an increase in susceptibility of the isolates to ampicillin and cotrimoxazole during the study period (2008-2013). Recommendation to use fluoroquinolones for empirical treatment in place of first line antibiotics may have contributed largely to the emergence of fluoroquinolones resistance.

This study documented $94 \%$ of sensitivity to ceftriaxone, this antibiotic may, therefore, be used as an alternative in the treatment of typhoid fever considering its low resistance proportions. Studies in Germany, India, and Nigeria [27-29] have however detected the presence of CTM-X gene group of extended-spectrum $\beta$-lactamase resistance (ESBL) that confers resistance to ceftriaxone. With recent reports from different countries reporting resistance to ceftriaxone, routine screening of such isolates is important.

\section{Limitations of the study}

We did not determine the MIC of all MDR isolates and the antibiotics tested and further detect the mutations associated with ciprofloxacin and nalidixic acid resistance that confer fluoroquinolones resistance.

\section{Conclusion}

Results from this study indicate that there is a significant variation in resistance pattern among $S$. Typhi isolates to the different antibiotic agents recommended for treatment. MDR $S$. Typhi strains are still high however continuous monitoring of susceptibility to the initial first line antibiotics is necessary since the MDR strains have lately shown increased susceptibility. In addition, there is an emergence of strains resistant and with intermediate susceptibility to ciprofloxacin. Therefore the use of ciprofloxacin for treatment of typhoid fever needs routine surveillance to prevent further spread of these strains.

\begin{abstract}
Abbreviations
AKUH: Aga Khan University Hospital; ATCC: American type culture collection; CDC: Centre for disease control and prevention; CLSI: Clinical and laboratory standards institute; ESBL: Extended-spectrum $\beta$-lactamase resistance; KEMRI: Kenya medical research institute; $\mathrm{KNH}$ : Kenyatta National Hospital; MDR: Multidrug resistant; MDRST: Multidrug resistant S.Typhi; MIC: Minimum inhibitory concentrations; NTPFS: National Typhoid and Paratyphoid Fever Surveillance System; WHO: World Health Organization
\end{abstract}

\section{Acknowledgements}

We would like to express our special gratitude to the entire Centre for Microbiology Research (CMR) laboratory staff at KEMRI for their technical support. We would also like to thank Dr. John Kiiru for assisting with the laboratory analysis of the samples and Dr. David Mutonga for data analysis. The director of CMR, Dr. Samuel Kariuki for laboratory support and for providing isolates to use in this study.

\section{Funding}

No funding was received.

\section{Availability of data and materials}

The de-identified datasets analysed during the current study are available from the corresponding author on reasonable request.

\section{Authors' contributions}

WM, AM, PW and SK were involved in designing the study and laboratory analysis of the research. WM performed the laboratory test, analyzed the data and drafted the manuscript. All authors read through and approved the manuscript.

\section{Ethics approval and consent to participate}

This study was approved by Kenya Medical Research Institute (KEMRI) Scientific Steering Committee and assigned SSC No. 1320. Since we used archived isolates to carry out the study we therefore did not have to seek consent from the participants.

\section{Consent for publication}

Not applicable.

\section{Competing interests}

The authors declare that they have no competing interests.

\section{Publisher's Note}

Springer Nature remains neutral with regard to jurisdictional claims in published maps and institutional affiliations.

\section{Author details}

${ }^{1}$ Department of Medical Microbiology, University of Nairobi, Nairobi, Kenya. ${ }^{2}$ School of Biological Sciences, Jomo Kenyatta University of Agriculture and Technology, Juja, Kenya. ${ }^{3}$ Centre for Microbiology Research, Kenya Medical Research Institute, Nairobi, Kenya.

Received: 5 December 2017 Accepted: 30 October 2018

Published online: 14 November 2018

References

1. Buckle GC, Walker CLF, Black RE. Typhoid fever and paratyphoid fever: Systematic review to estimate global morbidity and mortality for 2010. J Glob Health. 2012;2(1):10401 [cited 2017 Jan 27] Available from: http:// www.ncbi.nlm.nih.gov/pubmed/23198130.

2. Mogasale V, Mogasale W, Ramani E, Lee JS, Park JY, Lee KS, et al. Revisiting typhoid fever surveillance in low and middle income countries: lessons from systematic literature review of population-based longitudinal studies. 
BMC Infect Dis. 2015;16(1):35 [cited 2017 Jan 27] Available from: https:// www.ncbi.nlm.nih.gov/pubmed/26822522.

3. Mogasale V, Maskery B, Ochiai RL, Lee JS, Mogasale W, Ramani E, et al. Burden of typhoid fever in low-income and middle-income countries: a systematic, literature-based update with risk-factor adjustment. Lancet Glob Heal. 2014;2(10):e570-80 [cited 2017 Jan 27] Available from: http:// linkinghub.elsevier.com/retrieve/pii/S2214109X14703018.

4. Lee J-S, Mogasale W, Mogasale V, Lee K. Geographical distribution of typhoid risk factors in low and middle income countries. BMC Infect Dis. 2016;16(1):732 [cited 2017 Aug 10] Available from: http://www.ncbi.nlm.nih. gov/pubmed/27919235.

5. Srikantiah P, Girgis FY, Luby SP, Jennings G, Wasfy MO, Crump JA, et al. Population-based surveillance of typhoid fever in Egypt. Am J Trop Med Hyg. 2006;74(1):114-9 [cited 2017 Aug 10] Available from: http://www.ncbi. nlm.nih.gov/pubmed/16407354

6. Crump JA, Youssef FG, Luby SP, Wasfy MO, Rangel JM, Taalat M, et al. Estimating the incidence of typhoid fever and other febrile illnesses in developing countries. Emerg Infect Dis. 2003;9(5):539-44 [cited 2017 Aug 10] Available from: http://www.ncbi.nlm.nih.gov/pubmed/12737736.

7. Breiman RF, Cosmas L, Njuguna H, Audi A, Olack B, Ochieng JB, et al. Population-based incidence of typhoid fever in an urban informal settlement and a rural area in Kenya: implications for typhoid vaccine use in Africa. PLoS One. 2012;7(1):e29119 Gosling RD, editor. [cited 2017 Jan 31] Available from: http://dx.plos.org/10.1371/journal. pone.0029119.

8. Kariuki S, Gordon MA, Feasey N, Parry CM. Antimicrobial resistance and management of invasive Salmonella disease. Vaccine. 2015;33:C21-9 [cited 2017 Feb 7] Available from: http://www.ncbi.nlm.nih.gov/pubmed/ 25912288

9. CDC. Antibiotic Resistance Threats in the United States, 2013 | Antibiotic/ Antimicrobial Resistance | CDC. 2014 [cited 2017 Feb 3]. Available from: https://www.cdc.gov/drugresistance/threat-report-2013/

10. Crump JA, Mintz ED. Global trends in typhoid and paratyphoid Fever. Clin Infect Dis. 2010;50(2):241-6 [cited 2017 Sep 4] Available from: http://www. ncbi.nlm.nih.gov/pubmed/20014951.

11. Threlfall EJ, Ward LR, Rowe B, Raghupathi S, Chandrasekaran V, Vandepitte J, et al. Widespread occurrence of multiple drug-resistant Salmonella typhi in India. Eur J Clin Microbiol Infect Dis. 1992;11(11):990-3 [cited 2017 Sep 4] Available from: http://www.ncbi.nlm.nih.gov/pubmed/1295768.

12. Yan M, Li X, Liao Q, Li F, Zhang J, Kan B. The emergence and outbreak of multidrug-resistant typhoid fever in China. Emerg Microbes Infect. 2016;5(6): e62 [cited 2017 Jun 7] Available from: http://www.ncbi.nlm.nih.gov/ pubmed/27329848.

13. Sobhy Darwish W, Eldaly EA, Tharwat El-Abbasy M, Ikenaka Y, Nakayama S, Ishizuka M. Antibiotic residues in food: the African scenario. Jpn J Vet Res, 2013;61:13-22

14. CLSI. Performance Standards for Antimicrobial Susceptibility Testing; Twenty-Fifth Informational Supplement. CLSI document M100-S25. Wayne: Clinical and Laboratory Standards Institute; 2015.

15. Kariuki S, Gilks C, Revathi G, Hart CA. Genotypic analysis of multidrugresistant Salmonella enterica Serovar typhi, Kenya. Emerg Infect Dis. 2000; 6(6):649-51 [cited 2017 Aug 11] Available from: http://www.ncbi.nlm.nih. gov/pubmed/11076726.

16. Kariuki S, Revathi G, Muyodi J, Mwituria J, Munyalo A, Mirza S, et al. Characterization of multidrug-resistant typhoid outbreaks in Kenya. J Clin Microbiol. 2004;42(4):1477-82 [cited 2017 Feb 12] Available from: http:// www.ncbi.nlm.nih.gov/pubmed/15070992.

17. Mengo D, Uki S, Muigai A, Revathi G. Trends in Salmonella enteric serovar Typhi in Nairobi, Kenya from 2004 to 2006. J Infect Dev Ctries. 2010;4(6): 393-6 [cited 2017 11] Available from: https://jidc.org/index.php/journal/ article/view/503.

18. Shetty AK, Shetty IN, Furtado ZV, Antony B, Boloor R. Antibiogram of salmonella isolates from blood with an emphasis on nalidixic Acid and chloramphenicol susceptibility in a tertiary care hospital in coastal karnataka: a prospective study. J Lab Physicians. 2012;4(2):74-7 [cited 2017 Feb 13] Available from: http://www.ncbi.nlm.nih.gov/pubmed/23440906.

19. Chand HJ, Rijal KR, Neupane B, Sharma VK, Jha B. Re-emergence of susceptibility to conventional first line drugs in Salmonella isolates from enteric fever patients in Nepal. J Infect Dev Ctries. 2014;8(11):1483-7 [cited 2017 Feb 13] Available from: http://www.ncbi.nlm.nih.gov/pubmed/25390062.
20. Omulo S, Thumbi SM, Njenga MK, Call DR. A review of 40 years of enteric antimicrobial resistance research in Eastern Africa: what can be done better? Antimicrob Resist Infect Control. 2015;4:1 [cited 2017 Feb 1] Available from: http://www.ncbi.nlm.nih.gov/pubmed/25717374.

21. Matono T, Kato Y, Morita M, Izumiya H, Yamamoto K, Kutsuna S, et al. Case series of imported enteric fever at a referral center in Tokyo, Japan: antibiotic susceptibility and risk factors for relapse. Am J Trop Med Hyg. 2016;95(1):19-25 [cited 2017 Feb 7] Available from: http://www.ncbi.nlm.nih. gov/pubmed/27162265

22. Shrestha KL, Pant ND, Bhandari R, Khatri S, Shrestha B, Lekhak B. Reemergence of the susceptibility of the Salmonella spp. isolated from blood samples to conventional first line antibiotics. Antimicrob Resist Infect Control. 2016;5(1):22 [cited 2017 Feb 6] Available from: http://www.ncbi.nlm. nih.gov/pubmed/27231547.

23. Lutterloh E, Likaka A, Sejvar J, Manda R, Naiene J, Monroe SS, et al. Multidrug-resistant typhoid fever with neurologic findings on the MalawiMozambique Border. Clin Infect Dis. 2012;54(8):1100-6 [cited 2017 Aug 11] Available from: http://www.ncbi.nlm.nih.gov/pubmed/22357702.

24. Lunguya O, Lejon V, Phoba M-F, Bertrand S, Vanhoof R, Verhaegen J, et al. Salmonella Typhi in the Democratic Republic of the Congo:

Fluoroquinolone Decreased Susceptibility on the Rise. PLoS Negl Trop Dis. 2012;6(11):e1921 Ryan ET, editor. [cited 2017 Aug 11] Available from: http:// www.ncbi.nlm.nih.gov/pubmed/23166855.

25. Date KA, Newton AE, Medalla F, Blackstock A, Richardson LT, McCullough A, Mintz ED, Mahon BE. Changing Patterns in Enteric Fever Incidence and Increasing Antibiotic Resistance of Enteric Fever Isolates in the United States, 2008-2012. Clin Infect Dis. 2016;63(3):322-9. https://doi.org/10.1093/cid/ciw232.

26. Gandra S, Mojica N, Klein EY, Ashok A, Nerurkar V, Kumari M, et al. Trends in antibiotic resistance among major bacterial pathogens isolated from blood cultures tested at a large private laboratory network in India, 2008-2014. Int J Infect Dis. 2016;50:75-82 [cited 2017 Feb 13] Available from: https://www. ncbi.nlm.nih.gov/pmc/articles/PMC5063511.

27. Akinyemi KO, Iwalokun BA, Alafe OO, Mudashiru SA, Fakorede C. bla CTX-M-I group extended spectrum beta lactamase-producing Salmonella typhi from hospitalized patients in Lagos, Nigeria. Infect Drug Resist. 2015;8:99-106 [cited 2017 Feb 6] Available from: http://www.ncbi.n/m.nih.gov/pubmed/ 25999745.

28. Dutta S, Das S, Mitra U, Jain P, Roy I, Ganguly SS, et al. Antimicrobial resistance, virulence profiles and molecular subtypes of Salmonella enterica serovars Typhi and Paratyphi A blood isolates from Kolkata, India during 2009-2013. PLoS One. 2014;9(8):e101347 [cited 2017 Feb 7] Available from: http://www.ncbi.nlm.nih.gov/pubmed/25098613.

29. Pfeifer Y, Matten J, Rabsch W. Salmonella enterica serovar Typhi with CTX-M beta-lactamase, Germany. Emerg Infect Dis. 2009;15(9):1533-5 [cited 2017 Feb 7] Available from: http://wwwnc.cdc.gov/eid/article/15/9/09-0567_ article.htm.

\section{Ready to submit your research? Choose BMC and benefit from:}

- fast, convenient online submission

- thorough peer review by experienced researchers in your field

- rapid publication on acceptance

- support for research data, including large and complex data types

- gold Open Access which fosters wider collaboration and increased citations

- maximum visibility for your research: over $100 \mathrm{M}$ website views per year

At BMC, research is always in progress.

Learn more biomedcentral.com/submissions 